NOTE

\title{
Detection and quantification of Spironucleus barkhanus in experimentally infected Atlantic salmon Salmo salar
}

\author{
Fu Ci Guo, Patrick T. K. Woo* \\ Department of Zoology, University of Guelph, Guelph, Ontario NIG 2WI, Canada
}

\begin{abstract}
The course of Spironucleus barkhanus (Diplomonadida: Hexamitidae) infection in Atlantic salmon Salmo salar L. (Salmonidae) has 2 distinct phases, a blood phase and a tissue phase. To detect and quantify an infection, 3 parasitological techniques, namely Wet Mount Examination (WME), Hematocrit Centrifuge Technique (HCT) and the Hemocytometer (HCM) were used. In addition, 1 immunological technique, enzyme-linked immunosorbent assay (ELISA), was developed to detect specific antibodies against $S$. barkhanus. This technique would be particularly useful for epidemiological studies where large numbers of fish had to be examined. It would also be a good technique to detect infection during the tissue phase of the disease when there were no or a low number of parasites in the blood.
\end{abstract}

KEY WORDS: Spironucleus barkhanus $\cdot$ Diagnosis $\cdot$ ELISA $\cdot$ Salmo salar

Resale or republication not permitted without written consent of the publisher

\section{INTRODUCTION}

Systemic infections with high mortality caused by the flagellate Spironucleus barkhanus (family: Hexamitidae) were reported in Norwegian sea caged Atlantic salmon Salmo salar L. (Salmonidae) (Mo et al. 1990, Poppe et al. 1992, Poppe \& Mo 1993, Sterud et al. 1997). Since the outbreaks were natural infections, methods for detection and quantification of parasites and clinical diagnosis of the disease were not properly standardized. Our experimental study (Guo \& Woo 2004, this issue) indicates that there are blood and tissue phases in the infected Atlantic salmon and that $S$. barkhanus are not detectable in the blood during the tissue phase. If detection solely relied on blood examination, for example during routine surveys, then many infections would not be detected.

The present study explores the use of 3 parasitological and 1 immunological technique to detect Spironucleus barkhanus in experimentally infected Atlantic salmon to more accurately detect infections in fish. These techniques are commonly used for detecting haemoflagellate infections (Crytobia and Trypanosoma) in vertebrates (e.g. Woo 1970, Woo \& Kauffman 1971, Woo \& Wehnert 1983, Sitja-Bobadilla \& Woo 1994, Uilenberg 1998, Chin et al. 2004).

\section{MATERIALS AND METHODS}

Spironucleus barkhanus. The parasite strain was from the American Type Culture Collection (Rockville, Maryland, USA), ATCC 50377 (originated from muscle abscess in Atlantic salmon from Norway) and was subsequently maintained in our laboratory by intraperitoneal inoculation of live parasite in Atlantic salmon.

Atlantic salmon and infections. Hatchery raised juvenile Atlantic salmon were from the Ontario Ministry of Natural Resources and raised in the laboratory to sub-adult size (about $300 \mathrm{~g}$ ). Fish were kept in a circular tank with flow-through well water (temperature 10 to $11^{\circ} \mathrm{C}$ ) with continuous aeration, an equatorial lighting regime and were fed daily to satiation with commercial salmon feed (Martin's Feed). 
At $0 \mathrm{wk}$, fish were anaesthetized with 2-phenoxyethanol (Acrco Organics) before being injected with 50000 (5 fish), or 100000 (5 fish) live Spironucleus barkhanus in $0.2 \mathrm{ml}$ phosphate buffered saline (PBS, pH 7.2) (Expt A), and 60000 live $S$. barkhanus in $0.1 \mathrm{ml}$ PBS (Expt B, 4 fish). Mucus and blood samples were taken every week; mucus was always sampled before caudal blood sampling. About $0.1 \mathrm{ml}$ of blood was taken from the caudal vein using a heparinized needle and syringe. Mucus and blood were kept on ice until parasitaemias were determined. Dead fish were removed promptly from the tank and examined.

Parasitological techniques for parasite detection and quantification. Three techniques were used: (1) Fish blood was dispensed from a syringe into an Eppendorf brand $500 \mu \mathrm{l}$ centrifuge tube and the blood was drawn into heparinized $75 \mathrm{~mm}$ capillary tubes with one end sealed with Chā-seal (Chase Instruments), and centrifuged in a cold IEC MB centrifuge (Damon/IEC Division) at $13600 \times g$ for $2 \mathrm{~min}$. The 'buffy layer' (junction of the white cells and plasma) was observed under a microscope $(100 \times, 10 \times$ ocular and $10 \times$ objective) for motile parasites. The technique, called the Hematocrit Centrifuge Technique (HCT), was first described by Woo (1969) and was used for detecting Trypanosoma in mammalian blood (Woo 1970, Woo \& Kauffman 1971, Uilenberg 1998). The estimated number of parasites in the buffy layer determined whether the Wet Mount Examination (WME) or Hemocytometer (HCM) would be used for a more accurate parasite count. If fewer than 20 parasites were counted in the buffy layer, WME was used, while the HCM was used if over 20 parasites were counted. Briefly, for WME, $5 \mu \mathrm{l}$ of blood were pipetted onto a clean glass slide and a cover slip $\left(18 \times 18 \mathrm{~mm}^{2}\right)$ with 4 sides edged with petroleum gel was carefully pressed against the blood to create a monolayer of cells. The entire monolayer was scanned at $100 \times$ for parasites. Triplicate counts were performed. Briefly, for the HCM technique, a known volume of blood was diluted (up to 20 times by volume) with cold PBS, and $20 \mu \mathrm{l}$ of the diluted blood was loaded onto a hemocytometer (Improved Neubauer, Hausser Scientific). Parasite numbers were determined by counting the total numbers of live parasite in the white blood cell squares (Archer 1965) at a $100 \times$ magnification; 3 counts were performed for each fish, the number of parasites counted was multiplied by a dilution factor and expressed as number $\mathrm{ml}^{-1}$ of blood. (2) One drop of mucus (about $25 \mu \mathrm{l}$ ) was gently scraped from the fish body (above the lateral line) using a disposable wooden stick and loaded onto a chilled clean glass slide with the addition of $25 \mu \mathrm{l}$ of cold PBS. It was covered with a cover slip $\left(18 \times 18 \mathrm{~mm}^{2}\right)$ with 4 sides edged with petroleum gel. Parasite detection and quantifica- tion in the mucus followed the WME technique used for blood. The parasite number was expressed as number $\mathrm{ml}^{-1}$ of mucus. (3) Caseous necrotic fluid in skin ulcers was removed using a pipette. A known volume of cold PBS was added if necessary and WME or HCM was used to quantify the number of parasites in the resulting fluid. If organ nodules were found, the whole organ was dissected from the fish and weighed. An equivalent volume of cold PBS was added (e.g. $1 \mathrm{~g}$ of tissue was added to $1 \mathrm{ml}$ of PBS), the tissue squashed and ground, and the parasites counted using WME or the HCM directly or diluted further with PBS. The number of parasites was expressed as number $\mathrm{g}^{-1}$ of tissue or organ.

Immunological techniques. A blood sample from the caudal vein was blotted onto filter paper (No. 5, Whatman International), dried at room temperature for $3 \mathrm{~h}$ and stored at $-20^{\circ} \mathrm{C}$ until antibody detection using ELISA (enzyme-linked immunosorbent assay). One day before the assay, 1 disk (5.4 $\mathrm{mm}$ in diameter) was punched out from each blood blot and soaked in $75 \mu \mathrm{l}$ of dilution buffer (PBS with 0.1\% BSA [Sigma A7030]) in a well of a microplate (96 well, round bottom, Sarstedt) overnight at $4^{\circ} \mathrm{C}$. Three blots (triplicates) were analyzed for each fish. The ELISA was performed in flat bottom microplates (96 well, high binding polystyrene, Costar). Each well in the plate was coated with $50 \mu$ of coating buffer $\left(0.429 \mathrm{~g} \mathrm{Na}_{2} \mathrm{CO}_{3} \times 10 \mathrm{H}_{2} \mathrm{O}\right.$, $0.293 \mathrm{~g} \mathrm{NaHCO}_{3}$ in $100 \mathrm{ml}$ double distilled water, $\mathrm{pH}$ 9.6) containing $50 \mu \mathrm{g} \mathrm{ml}^{-1}$ of sonicated Spironucleus barkhanus antigen (from axenic cultures of $S$. barkhanus in a modified Diamond's TYI-S-33 medium) (Diamond et al. 1978, Sterud 1998). Total protein content was measured using the Bio-Rad Protein Assay and incubated at $37^{\circ} \mathrm{C}$ for $60 \mathrm{~min}$. The plate was washed 5 times with PBST (PBS with $0.3 \%$ Tween-20, Bio-Rad). Blocking buffer (200 $\mu \mathrm{l}$ of $5 \%$ non-fat dry milk in PBS) was added (to block uncoated sites) for $30 \mathrm{~min}$ at $37^{\circ} \mathrm{C}$. The plate was washed 5 times with PBST and then, $50 \mu \mathrm{l}$ of eluant (1st antibody) from the blood blot were added to a well and incubated for $60 \mathrm{~min}$ at $37^{\circ} \mathrm{C}$. The plate was washed 5 times with PBST and $50 \mu \mathrm{l}$ of rabbit anti-salmon IgG (2nd antibody, diluted 1:1000, courtesy of Dr. K. Buchmann, The Royal Veterinary and Agricultural University, Denmark) were added and incubated for 30 min at $37^{\circ} \mathrm{C}$. The plate was washed 5 times with PBST and $50 \mu \mathrm{l}$ of peroxidase-conjugated goat anti-rabbit IgG (Sigma A3687, 3rd antibody, diluted 1:10 000) were added and incubated for $30 \mathrm{~min}$ at $37^{\circ} \mathrm{C}$. The plate was washed 5 times with PBST and $50 \mu \mathrm{l}$ of enzyme substrate (Orthophenylenediamine, Sigma P5412) were added and the plate was kept in the dark for 15 to $20 \mathrm{~min}$. The reaction was stopped by the addition of $25 \mu \mathrm{l}$ of $9 \mathrm{M}$ $\mathrm{H}_{2} \mathrm{SO}_{4}$ to each well and the color intensity was mea- 
sured using a microplate reader (Molecular Devices) at $492 \mathrm{~nm}$. Wells with only the 2nd and 3rd antibodies and substrate were included as a negative control (background non-specific binding). In addition, wells with naïve serum (as Negative Reference OD), pretested antiserum from recovered fish (Positive Reference OD) and additional quality control wells such as no antigen wells, substrate and 3rd antibody wells were also included in each plate.

The following formula was used for calculating the ELISA Value (EV) (after Sitja-Bobadilla \& Woo 1994):

$\mathrm{EV}=\frac{\text { Infected fish OD }- \text { Negative Reference OD }}{\text { Positive Reference OD }- \text { Negative Reference OD }} \times 100$

The Negative Reference OD was obtained from 18 naïve fish (10 i.p. with PBS, 8 not inoculated). The Positive Reference OD was from 3 infected fish that had recovered from spironucleosis.

Statistics. All data were analyzed using 1-way ANOVA and multiple comparisons among means were made with Duncan's multiple-Range Test.

\section{RESULTS AND DISCUSSION}

\section{Parasitological techniques}

Spironucleus barkhanus was detected in the blood using the HCT in 3 fish (out of 10, Expt A) at 1 wk post infection (wpi) and 4 fish at 2 wpi, but WME did not detect any $S$. barkhanus at 1 and 2 wpi. At 3 wpi, 8 fish were positive using WME and the HCT, and parasitaemias ranged from 57 to $1700 \mathrm{ml}^{-1}$ blood. All 10 fish were positive using the HCT and WME at 4 wpi, and parasitaemias ranged from 20 to $118000 \mathrm{ml}^{-1}$ blood. By 6 wpi, 6 fish became negative for $S$. barkhanus in the blood using the HCT and WME, and average parasitaemia increased to $175627 \mathrm{ml}^{-1}$ blood (counted using the HCM). By 7 wpi, only 2 fish were positive, the average parasitaemia peaked (221964 $\mathrm{ml}^{-1}$ blood using the HCM), and at 8 wpi only 1 fish had detectable $S$. barkhanus with only 133 parasites $\mathrm{ml}^{-1}$ blood (counted using WME). From 9 wpi onwards, no $S$. barkhanus was detected in the blood using either the HCT or WME.

The HCT is a well-established technique for the detection of haemoflagellates such as Trypanosoma in mammals (Woo 1970, Woo \& Kauffman 1971, Uilenberg 1998) or Cryptobia in salmonids (Woo 1979, Woo \& Wehnert 1983, Ardelli \& Woo 2002). In the present study, the HCT was found to be useful for the detection of the blood phase of Spironucleus barkhanus. Woo (1979) initially reported a higher sensitivity with WME than the HCT in detecting Cryptobia salmositica; however, the sensitivity of the HCT was significantly better than WME if the centrifugation was at $5^{\circ} \mathrm{C}$ as the haemoflagellate is a parasite of cold water fish (Woo \& Wehnert 1983).

By using WME, Spironucleus barkhanus was found in the mucus of an infected fish (Expt B) with nonobvious skin lesions and parasitaemias were 80 and $160 \mathrm{ml}^{-1}$ of mucus at 9 and $10 \mathrm{wpi}$, respectively. WME was used to detect parasites in the ascites fluid and followed by using the HCM to obtain the parasitaemia (e.g. $4.2 \times 10^{6} S$. barkhanus $\mathrm{ml}^{-1}$ of ascites fluid in a 12 wpi fish, Expt A). WME and HCM were used simultaneously to detect and quantitate parasites in the tissue phase, such as granulomatous lesions (white nodules) of liver and spleen (1 fish died at 14 wpi in Expt A with liver and spleen lesions; parasitaemias were $3.3 \times$ $10^{6}$ and $4.8 \times 10^{6} \mathrm{~g}^{-1}$, respectively), exophthalmia (1 fish died at 12 wpi in Expt A with $4.4 \times 10^{6} \mathrm{ml}^{-1}$ of $S$. barkhanus in the eye socket and $0.2 \times 10^{6} \mathrm{ml}^{-1}$ in the vitreous humor) and skin ulcers (1 fish in Expt A died at 20 wpi with a parasitaemia of $2.8 \times 10^{6} \mathrm{ml}^{-1}$ in the ground muscle tissue from the ulcer).

The 3 parasitological techniques were found to be useful in detecting and enumerating parasites in the blood, mucus, ascites fluid, lesion/ulcer nodules and bulged eyeball, during blood and tissue phases of Spironucleus barkhanus infection. For the blood phase, it was convenient to start with the HCT because packed cell volume can also be obtained, followed by WME or the HCM depending on the number estimated from the buffy layer. For the tissue phase, WME was the first choice. If parasite number was over $10000 \mathrm{ml}^{-1}$, the HCM was adopted because it was less time consuming than WME.

\section{Immunological technique (Fig. 1)}

The EV formula provided relative values, which were obtained by comparing the sample OD readings with OD readings of naïve and infected fish. EVs of less than 25 were regarded as background (the value was derived from a control group of 10 fish, which had EVs of 25 or less; these readings were probably due to non-specific binding).

The ELISA was sensitive in detecting significant increases of antibody production $(p<0.05)$ at $7,8,9$ and 11 wpi. Antibody titer was highest 1 wk after peak parasitaemia. There was a second peak (11 wpi) of antibody production and this probably correlated to the peak of tissue phase infection as mortality was high (Fig. 1). ELISA can be used to detect Spironucleus barkhanus infection during the periods $(8,9$ and 11 wpi) when the parasites are not detectable in the blood. It is sensitive and reproducible. This immunological technique has another advantage as it uses 


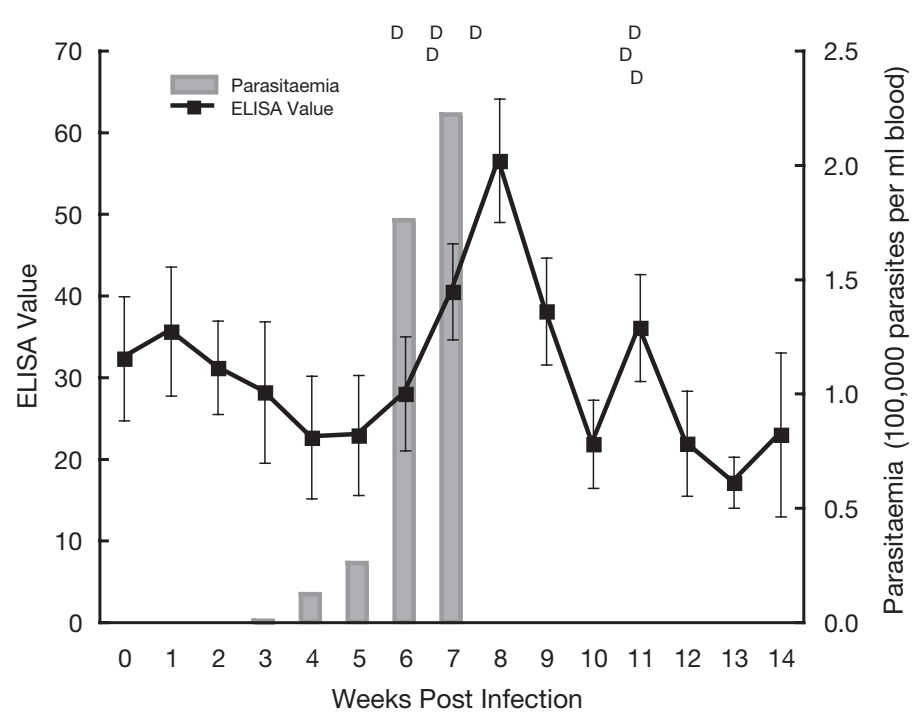

Fig. 1. Anti-Spironucleus barkhanus antibody and blood parasitaemia in experimentally infected Atlantic salmon Salmo salar (note: D = fish death; 8 out of 10 fish died of spironucleosis by $14 \mathrm{wk}$ post infection [wpi], consequently ELISA values [EV] were not shown after $14 \mathrm{wpi}$ )

dried blood samples on filter paper and would be useful for large epidemiological surveys for $S$. barkhanus infection in Atlantic salmon or in carrier fish, especially when fish do not have clinical signs of spironucleosis. Obviously, further work is required to test the reliability of this technique under field conditions.

Acknowledgements. This study was supported by a grant from the Natural Sciences and Engineering Research Council (Canada) to P.T.K.W.

\section{LITERATURE CITED}

Archer RK (1965) Haematological techniques for use on animals. Blackwell, Oxford

Ardelli BF, Woo PTK (2002) Experimental Cryptobia salmositica (Kinetoplastida) infections in Atlantic salmon, Salmo salar L.: cell-mediated and humoral immune responses against the pathogenic and vaccine strains of the parasite. J Fish Dis 25:265-274

Chin A, Guo FC, Bernier NJ, Woo PTK (2004) Effect of Cryptobia salmositica-induced anorexia on feeding behavior

Editorial responsibility: Wolfgang Körting,

Hannover, Germany and immune response in juvenile rainbow trout Oncorhynchus mykiss. Dis Aquat Org 58:17-26

Diamond LS, Harlow DR, Cunnick CC (1978) A new medium for the axenic cultivation of Entamoeba histolytica and other Entamoeba. Trans R Soc Trop Med Hyg 72:431

Guo FC, Woo PTK (2004) Experimental infections of Atlantic salmon Salmo salar with Spironucleus barkhanus. Dis Aquat Org 61:59-66

Mo TA, Poppe TT, Iversen L (1990) Systemic hexamitosis in salt-water reared Atlantic salmon (Salmon salar L.). Bull Eur Assoc Fish Pathol 10:69

Poppe TT, Mo TA (1993) Systemic, graulomatous hexamitosis of farmed Atlantic salmon: interaction with wild fish. Fish Res 17:147-152

Poppe TT, Mo TA, Iversen L (1992) Disseminated hexamitosis in sea-caged Atlantic salmon Salmo salar. Dis Aquat Org 14:91-97

Sitja-Bobadilla A, Woo PTK (1994) An enzyme-linked immunosorbent assay (ELISA) for the detection of antibodies against the pathogenic haemoflagellate, Cryptobia salmositica Katz and protection against cryptobiosis in juvenile Oncorhynchus mykiss (Walbaum) inoculated with a live Cryptobia vaccine. J Fish Dis 17:399-408

Sterud E (1998) In vitro cultivation and temperature dependent growth of two strains of Spironucleus barkhanus (Diplomonadida: Hexamitidae) from Atlantic salmon Salmo salar and grayling Thymallus thymallus. Dis Aquat Org 33:57-61

Sterud E, Mo TA, Poppe TT (1997) Ultrastructure of Spironucleus barkhanus n. sp. (Diplomonadida: Hexamitidae) from grayling Thymallus thymallus (L.) (Salmonidae) and Atlantic salmon Salmon salar L. (Salmonidae). J Eukaryot Microbiol 44:399-407

Uilengerg G (1998) A field guide for the diagnosis, treatment and prevention of African animal trypanosomosis. Food and Agriculture Organization of the United Nations, Rome

Woo PTK (1969) The haematocrit centrifuge technique for the detection of trypanosomes in blood. Can J Zool 47: 921-923

Woo PTK (1970) The haematocrit centrifuge technique for the diagnosis of African trypanosomiasis. Acta Tropica 27: 384-387

Woo PTK (1979) Trypanoplasma salmositica: experimental infections in rainbow trout, Salmo gairdneri. Exp Parasitol 47:36-48

Woo PTK, Kauffman M (1971) The haematocrit centrifuge technique for the detection of low virulent strains of trypanosomes of the Trypanosoma congolense sub-group. Acta Tropica 28:304-308

Woo PTK, Wehnert SD (1983) Direct transmission of a haemoflagellate, Cryptobia salmositica Katz 1951 (Kinetoplastida: Bodonina) between rainbow trout under laboratory conditions. J Protozool 39:334-337

Submitted: March 30, 2004; Accepted: July 5, 2004

Proofs received from author(s): September 1, 2004 